NASA Technical Memorandum 88804

AIAA-86-1557

\title{
Visualization of Flows in a Motored Rotary Combustion Engine Using Holographic Interferometry
}

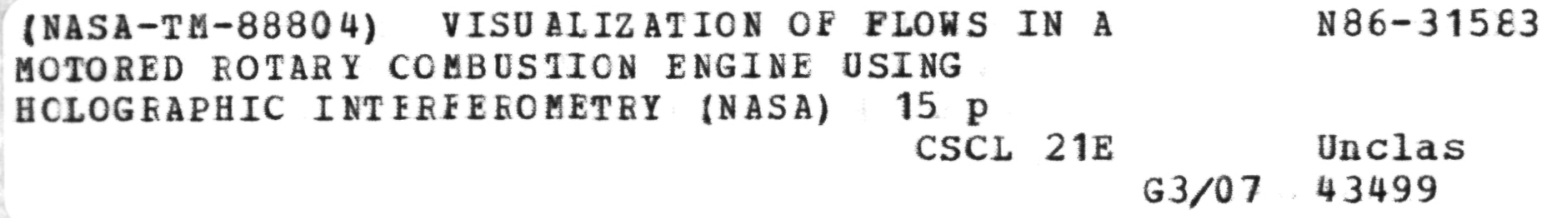

Yolanda R. Hicks and Harold J. Schock

Lewis Research Center

Cleveland, Ohio

and

James E. Craig, Holly L. Umstatter, and David Y. Lee Spectron Development Laboratories, Inc.

Costa Mesa, California

Prepared for the

22nd Joint Propulsion Conference

cosponsored by the AIAA, ASME, SAE, and ASEE

Huntsville, Alabama, June 16-18, 1986 
VISUALIZATION OF FLOWS IN A MOTORED ROTARY COMBUSTION

\title{
ENGINE USING HOLOGRAPHIC INTERFEROMETRY
}

\author{
Yolanda R. Hicks and Harold J. Schock \\ National Aeronautics and Space Administration \\ Lewis Research Center \\ Cleveland, Ohio 44135
}

\author{
and \\ James E. Craig, Holly L. Umstatter, and David Y. Lee \\ Spectron Development Laboratories, Inc. \\ 3303 Harbor Blvd., Suite G-3 \\ Costa Mesa, California 92626
}

\section{SUMMARY}

This paper describes the use of holographic interferometry to view the small- and large-scale flow field structures in the combustion chamber of a motored Wankel engine assembly. In order that the flow patterns of interest could be observed, small quantities of helium were injected with the intake air. Variation of the air flow patterns with engine speed, helium flow rate, and rotor position are described. The air flow at two locations within the combustion chamber was examined using this technique.

\section{INTRODUCTION}

The rotary engine, because of its high power-to-weight ratio and multifuel capability, is being studied for its potential use as the future powerplant for light aircraft. Experimental determination of an optimum combustion chamber and structural geometry using the traditional "cut-and-try" approach would be very expensive, if not impossible, from a technical viewpoint. In order to design rotary engines which are fuel efficient, and have high power densities, fundamental research is being performed to understand the physics and thermodynamics involved in the combustion process. Part of this research involves experimental combustion chamber air flow studies which complement numerical simulations of the combustion process in the rotary engine (refs. 1 and 2). When validated multi-dimensional models have been developed, they will be used to design rotary engines capable of burning overall lean fuel-air mixtures at operating speeds as high as $10000 \mathrm{rpm}$. These codes will also be used to provide input boundary conditions to three-dimensional rotary engine structural analysis simulations.

This paper describes the development and initial application of a holographic interferometry system to study air flow in the combustion chamber of a rotary engine. Holographic interferometry is a well established flow visualization tool from both qualitative and quantitative viewpoints (refs. 3 to 9), although it has not been previously applied to the rotary engine. The fringe patterns produced using this technique result from variations in the index of refraction within the fluid, so that very precise measurements of density can be made. This work represents the first published visualization of the small and large air flow structures in the rotary engine. 
The test assembly, as shown in figure 1 , is a single rotor, peripherally ported Wankel configuration, driven by a three-phase alternating current motor. This assembly was designed for use in flow visualization and measurement.

Design objectives were to provide as large a field of view into the combustion chamber as possible, while maintaining the strength and stability necessary to withstand the pressure and thermal shock of firing. Therefore, side housings of stainless steel were designed with window ports and water cooling passages. The windows are placed in the housings so that much of the combustion cycle is observable; however, events at top-dead-center (TDC) are not viewable. Sapphire was selected as the window material because of its strength, hardness, and optical clarity.

The initial assembly design utilized oil for lubrication; upon initial testing of the engine, the 011 was found to become deposited on the windows. This causes such serious optical aberrations that no useful data could be obtained. A dry lubrication system was used to eliminate this problem. The rotor bearings were replaced with oil impregnated bearings and the oil, side, corner, and apex seals were replaced with dry lubricant seals made of a graphite-impregnated polyimide. Initial tests with these modifications were successful. A thin film of the polyimide was left on the windows at start up. The injection of a solvent (methanol) through the intake port causes breakdown of this film. The side seals then sweep the solution away as they pass over the windows, leaving the windows clean.

\section{EXPERIMENTAL SET-UP AND PROCEDURE}

Figure 2 shows the experimental configuration used. A pulsed, q-switched ruby laser $(\lambda=0.694 \mu \mathrm{m}$, pulsewidth $=30.0 \mathrm{nsec})$ was used in a double pass, reference beam path-matched system to record the flow field during intake and the beginning of compression. A beam stop filter was used to eliminate a strong first window reflection which would otherwise severely degrade the interferogram of interest. Initial testing indicated that the air density changes were too small to be recorded using this system. To obtain an estimate of the flow structures in the intake, a small amount of the helium was introduced during intake at either the top or the bottom of the intake port (depend. ing on the experiment).

Figure 3 details the five rotor positions studied, ranging from $260^{\circ}$ to $530^{\circ}$ before $T D C$ along a single rotor face. The laser was triggered at a prespecified shaft crank angle using a NASA-designed electronic device (ref. 10). The electronic pulse box received angular information from a shaft angle encoder. A phase angle of $0^{\circ}$ was set on the pulse box to coincide with TDC on the rotor face immediately preceding that of the rotor face of interest, so that rotor position III, which corresponds to 0.0 phase degrees, is $360^{\circ}$ BTDC. The optics were aligned to provide two different fields of view through the engine for flow field recording, as shown in figure 4 . Position 1 contains a view of the intake port. Position 2, whose field slightly overlaps that of position 1, provides a view later in the intake stroke.

Two types of double exposure interferograms were made. Type one allows observation of the large-scale mixing of helium with air and is made by first taking one exposure without helium and a second exposure later at the same 
crank angle with helium on. This is referred to as a double exposure interferogram in this study. The second type of holograms made were rapid double exposure interferograms which provide higher frequency information. These are referred to as double pulse interferograms in this study. The pulse separation was typically $200 \mu \mathrm{s}$, although some events were recorded with a pulse separation of $50 \mu \mathrm{s}$. At $500 \mathrm{rpm}$ the rotor moves $0.20^{\circ}$ during $200 \mu \mathrm{s}$.

\section{RESULTS AND DISCUSSION}

Based on the preceding discussions, the system was judged ready to begin the initial application/feasibility demonstration phase of the program. This section presents and evaluates a limited amount of initial experimental data from a measurement-feasibility point of view. Data analys is is divided into three parts. First, the intake cycle is examined in sequence as the rotor moves through the cycle ending with compression. Second, the effect of helium flow rate on the flow field is analyzed. Finally, the effect of engine speed on the flow pattern is analyzed.

The mixing of intake air with 10 psig helium injected at the top of the intake port is now reviewed through the intake cycle, at each of the five rotor positions outlined above as the rotor moves toward the compression stroke.

Examination of the air flow at rotor position I ( $529.4^{\circ}$ BTDC) shows that substantial mixing occurs in the areas adjacent to and below the helium jet, as indicated by the high frequency and closed fringes in figure 5 . Little mixing occurs above the injection point, as indicated by the minimal fringe activity in the double pulse interferogram of figure $5(a)$ and the straighter and lower-density fringes in the double exposure interferogram of figure $5(b)$.

Halfway through intake, at $460.65^{\circ}$ BTDC (fig. 6), it can be seen that the helium vortices which are formed and pulled down in front of the intake port change significantly within $50 \mu \mathrm{s}$. Longer pulse separation also shows significant mixing below the jet, whereas the region above the injection point shows less activity. The double exposure interferogram (fig. 6(c)) confirms this summation.

Examination of the air flow at position III, $360^{\circ}$ BTDC, shows that the flow characteristics here are similar to those at position II. Intense mixing takes place in front of the intake port just below the injection point and the helium soon becomes well mixed, as shown in figure 7(a). Figure 7(b), a double pulse interferogram, and figure $7(\mathrm{c})$, a double exposure interferogram, both show the view at optics position 2 and confirm that little mixing occurs downstream of the intake port.

As the end of intake approaches, with the intake port half closed (fig. 8), substantial mixing activity is still apparent near the intake port (fig. 8(a)). There is minimal mixing further in the chamber as the helium attaches itself to the rotor face (fig. 8(b)). As the compression stroke begins, mixing is observed to occur only along the rotor face (fig. 9).

The effect of varying the helium flow rate is now reviewed. Figure 10 , which shows the flow field at Position IV and $500 \mathrm{rpm}$, illustrates this effect quite well. In figure 10(a), helium enters the combustion chamber at $20 \mathrm{psig}$ and attaches to the rotor face, where little mixing occurs. Some mixing down- 
stream can be observed in figure 10(a). Helium at 10 psig (fig. 10(b)) shows a substantial contrast. Again, helium moves to attach to the rotor face; however, the jet is not preserved as far into the chamber as in the previous case. Note also that some of the flow is pulled upward toward the outer edge of the combustion chamber, then back down toward the rotor face at a point downstream, as shown by the closely spaced fringes at the right. The flow field with 6 psig helium is similar to the flow field using 10 psig helium. Figure $10(\mathrm{c})$ shows that helium at the rotor face has mixed more readily with the intake air and that the flow is well mixed downstream. The flow which was pulled upward at 10 psig helium disperses upward more quickly at 6 psig helium pressure.

Figure 11 compares flow fields in compression in which the helium flow rate was varied. More mixing occurs at 20 psig (fig. $11(a)$ ), than at 10 or 6 psig (figs. 11(b) and (c)). This is probably because most of the helium available for mixing at the lower helium flow rate has already mixed with the air. In the same time frame, and with essentially twice as much helium entering the combustion chamber, the 20 psig helium has yet to become well mixed. This points out the need to assess the influence of the helium jet on the air flow in the engine assembly.

The effect of engine speed on the mixing pattern is now reviewed. Figure 12 demonstrates the effect of engine speed on the flowfield. Figure 12(a) shows $10 \mathrm{psig}$ helium at $652 \mathrm{rpm}$; figure 12(b) shows $10 \mathrm{psig}$ helium at $510 \mathrm{rpm}$. The greater engine speed seems to induce a higher turbulence level which causes the helium to mix more evenly throughout the combustion chamber at $652 \mathrm{rpm}$ than at $510 \mathrm{rpm}$.

\section{SUMMARY AND CONCLUSIONS}

The feasibility of using the motored engine assembly designed and built by NASA was successfully demonstrated for flow visualization in the oilless configuration. Use of a conventional oil lubrication system caused aberrations which were impossible to subtract.

For the optical configuration used, it was necessary to introduce small amounts of helium to provide sufficient density gradients within the flow to produce refraction-induced fringes.

From the limited amount of data taken in these experiments, it was found that greater fringe activity appeared in the shear layers near the inlet port than in the area away from the inlet. As the primary purpose of this experiment was to demonstrate the viability of the flow visualization system used with the rotary engine assembly, no attempt was made to identify turbulence induced by the helium jet. As the area ratio of the intake air port to the helium jet was about 200:1, one would not expect activity over a significant part of the flow field to be a result of the helium jet; however, formation of the large scale (low frequency) fringes was affected by the helium flow rate. It is clear that the optimum helium flow rates have yet to be established.

Slightly larger scale high frequency structures were observed at $510 \mathrm{rpm}$ than at $652 \mathrm{rpm}$. 


\section{REFERENCES}

1. Willis, E.A. and Wintucky, W.T., "An Overview of NASA Intermittent Combustion Engine Research," AIAA Paper 84-1393, June 1984.

2. Shih, T. I-P., Yang, S.L. and Schock, H.J., "A Two-Dimensional Numerical Study of the Flow Inside the Combustion Chamber of a Motored Rotary Engine," SAE Paper 860615, Feb. 1986.

3. Witte, A.B., Fox, J. and Rungaldier, H., "Localized Measurements of Wake Density Fluctuations Using Pulsed Laser Holographic Interferometry, " AIAA Journal, Vol. 10, No. 4, Apr. 1972, pp. 481-487.

4. Witte, A.B. and Wuerker, R.F., "Laser Holographic Interferometry Study at High Speed Flowfields," AIAA Journal, Vo1. 8, No. 3, Mar. 1970, pp. 581-583.

5. Matulka, R.D. and Collins, D.J., "Determination of Three-Dimensional Density Fields from Holographic Interferograms," Journal of Applied Physics, Vol. 42, No. 3, Mar. 1, 1971, pp. 1109-1119.

6. Trolinger, J.D., "Flow Visualization Holography," Optical Engineering, Vol. 14, No. 5, Sept.-Oct. 1975, pp. 470-481.

7. Brooks, R.E., Heflinger, L.0. and Wuerker, R.F., "Pulsed Laser Holograms," IEEE Journal of Quantum Electronics, Vol. QE2, No. 8, Aug. 1966, pp. 275-279.

8. Howes, W.L. and Buchele, D.R., "A Theory and Method for Applying Interferometry to the Measurement of Certain Two-Dimensional Gaseous Density Fields," NACA TN-2693, 1952.

9. Trolinger, J.D., "Diagnostics of Turbulence by Holography, " Advances in Laser Technology for the Atmospheric Sciences, edited by J. Trolinger and W.W. Moore, SPIE Vol. 125, SPIE, Bellingham, WA, 1977, pp. 105-113.

10. Chun, K.S., "Synchronization Trigger Control System for Flow Visualization," In Preparation - to be published as a NASA TM. 
ORIGINAL PRE W

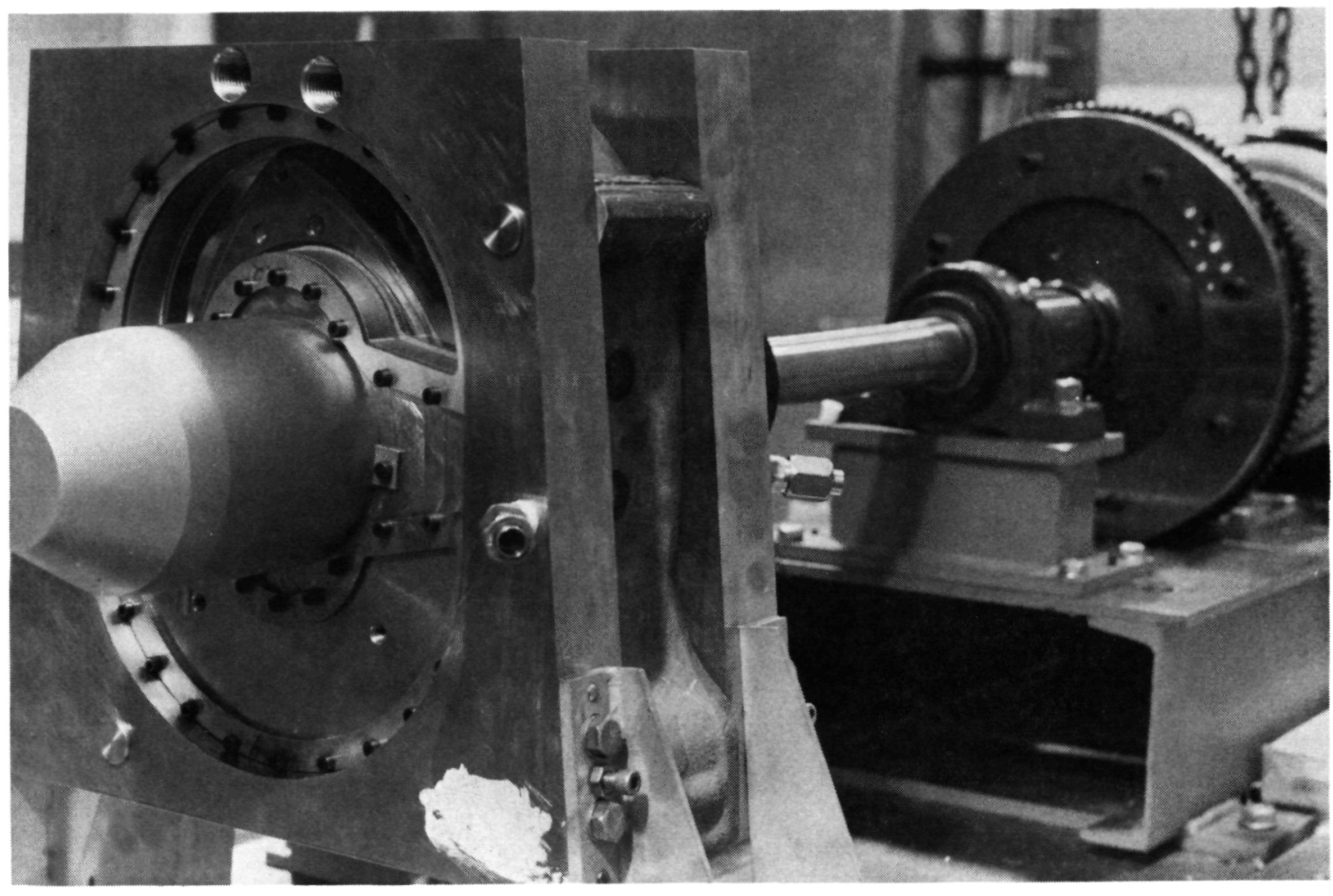

Figure 1. -ROTARY ENGINE TEST ASSEMBLY. 


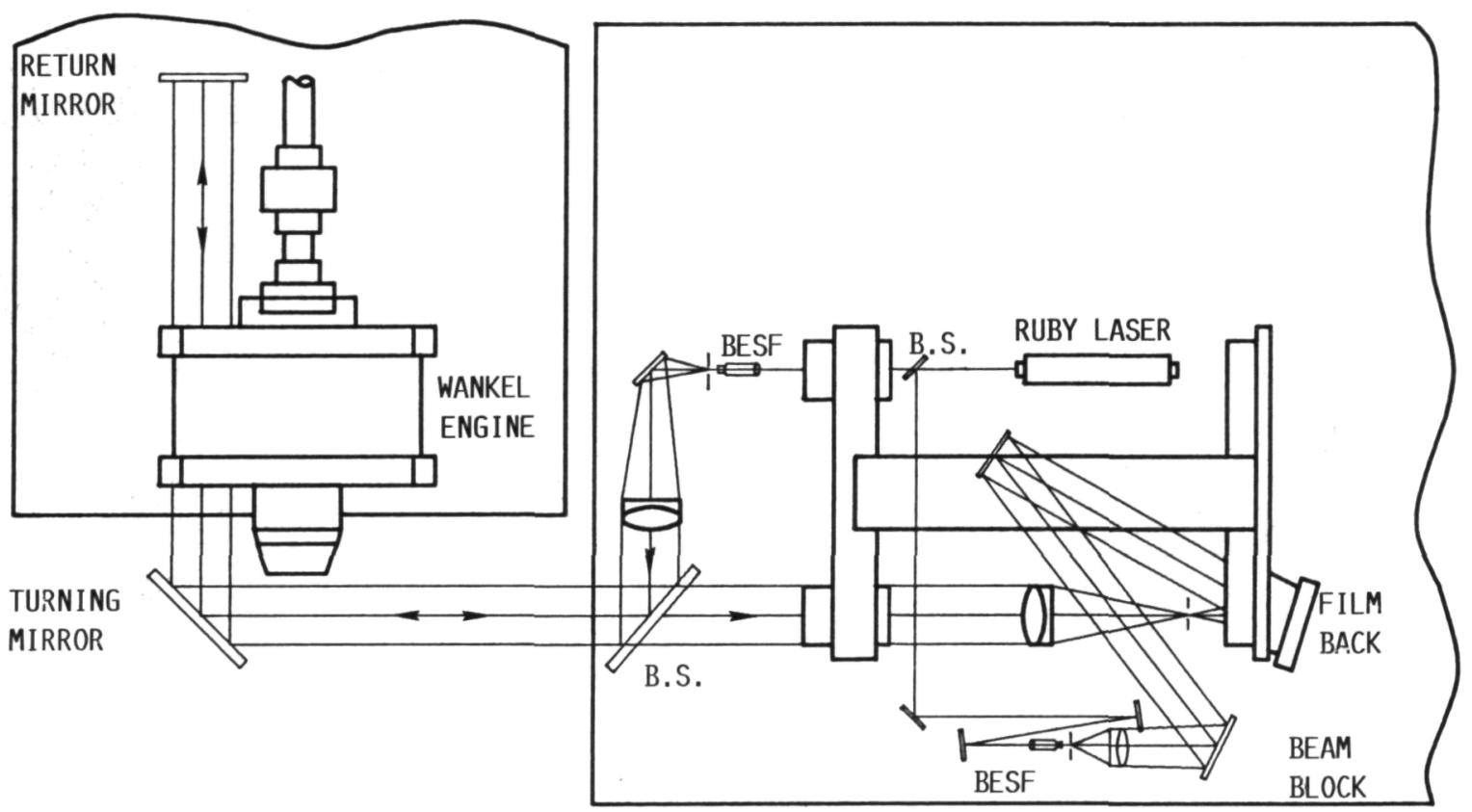

FIGURE 2. - OPTICAL CONFIGURATION FOR DOUBLE PASS HOLOGRAPHIC INTERFEROMETRY. 


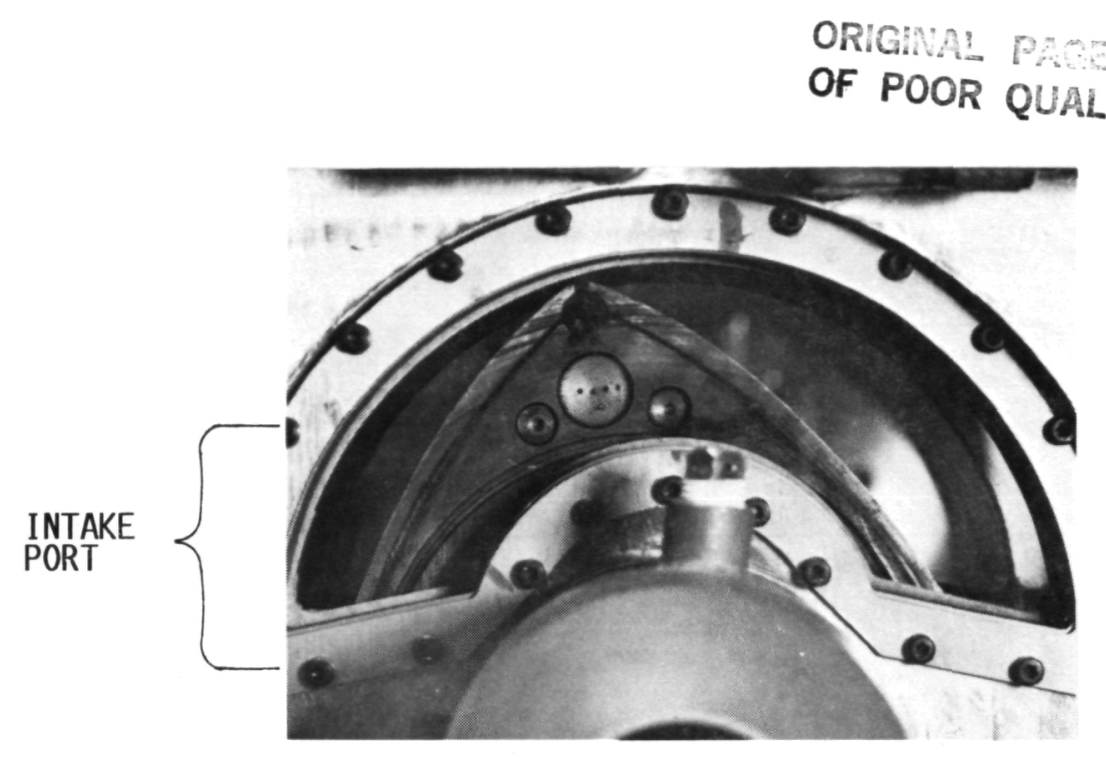

(A). Position I, 529.4 ${ }^{\circ}$ BTDC.

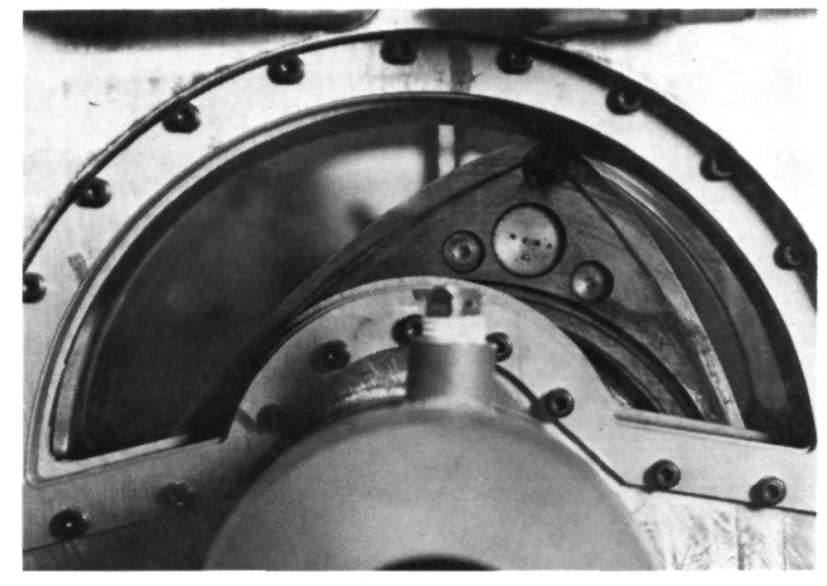

(B). Position II, $460.65{ }^{\circ}$ BtDC.

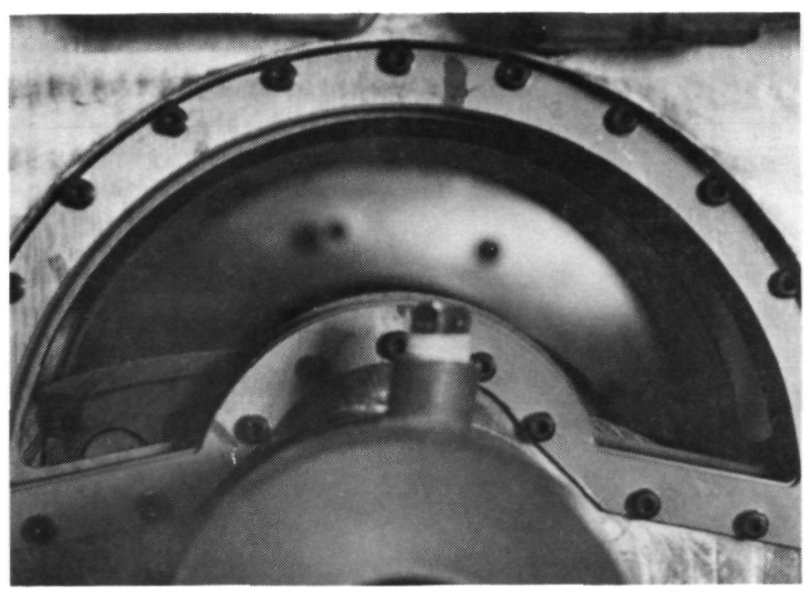

(D). Position IV, $300{ }^{\circ}$ BTDC.

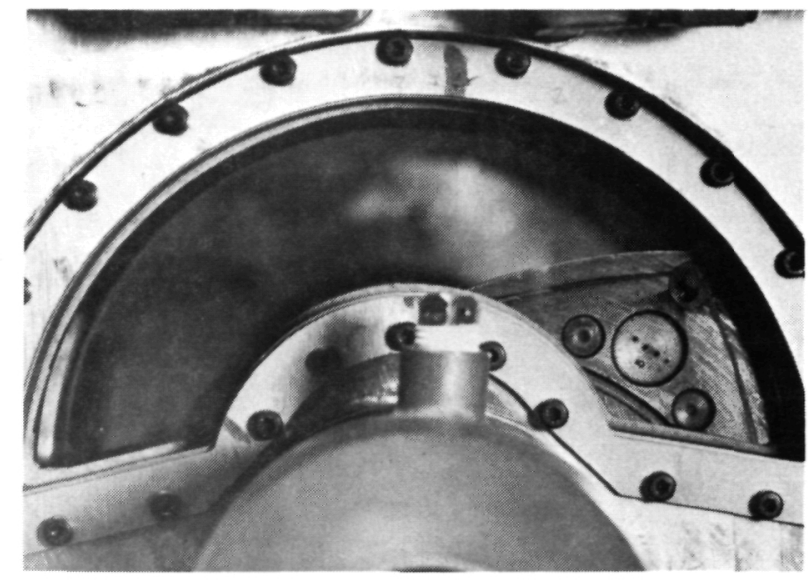

(c). Position ili, $360^{\circ}$ BTDC.

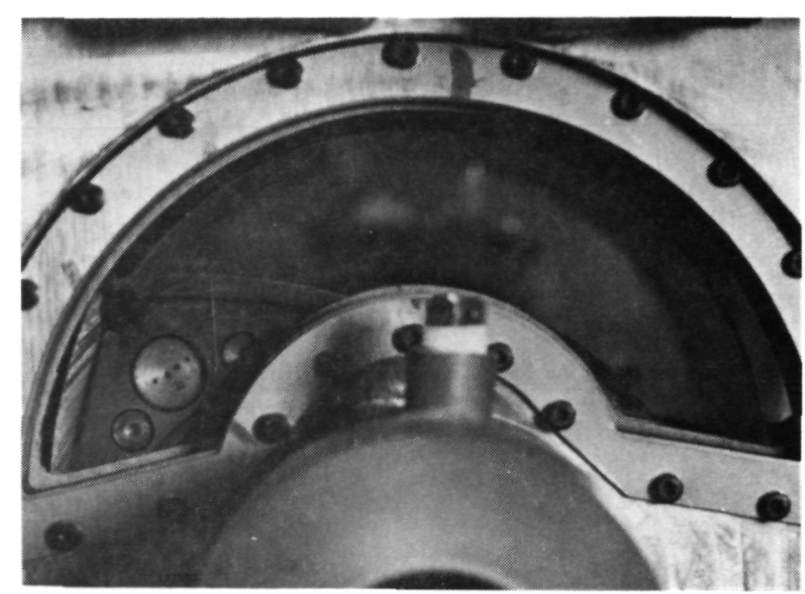

(E). Position V. $261.6{ }^{0} \mathrm{BTDC}$.

FIGURE 3. - ROTOR POSITIONS USED FOR HOLOGRAPHIC RECORDING. 


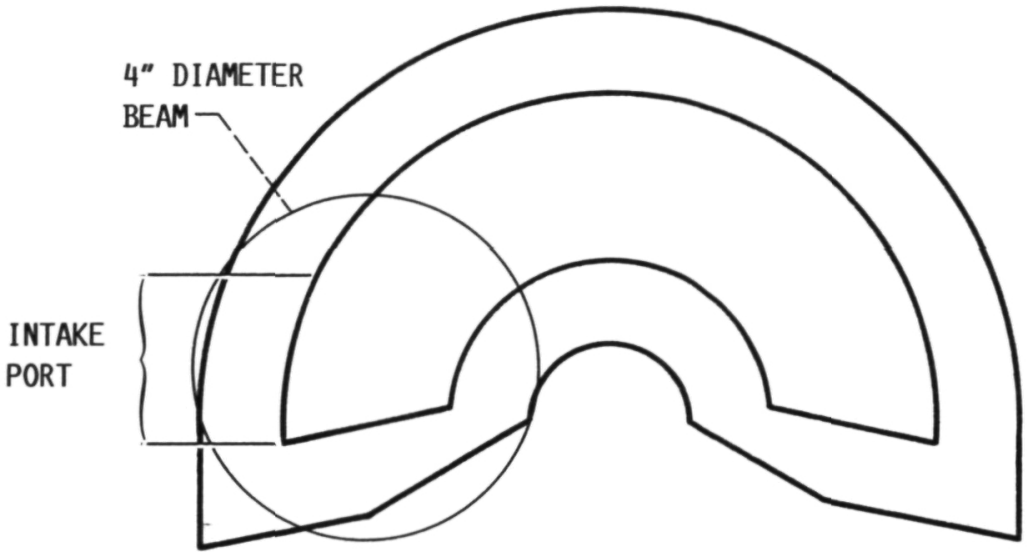

(A) First FiELD OF VIEW.

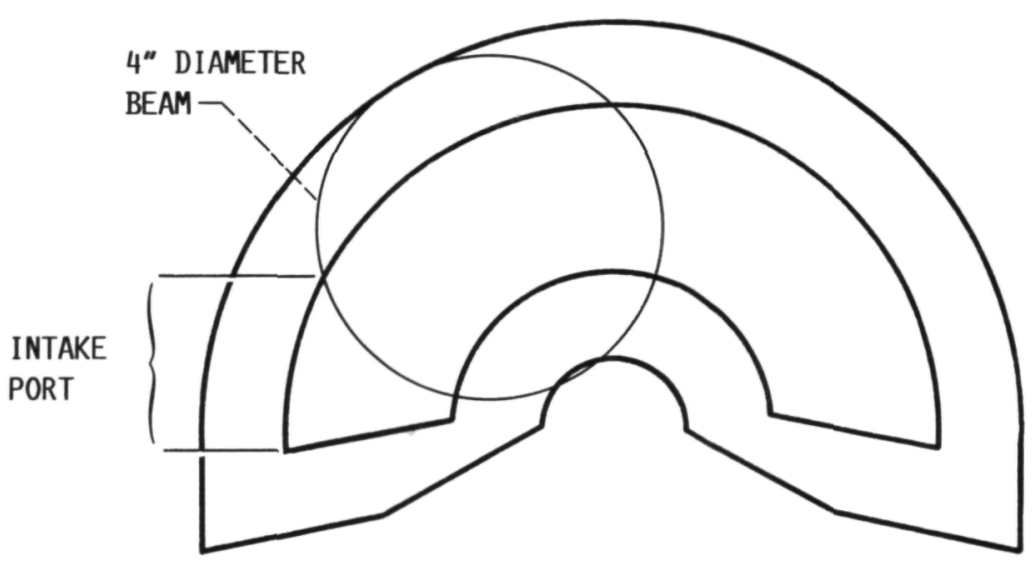

(B) SECOND FIELD OF VIEW.

Figure 4.- FieldS OF VIEW FOR HOLOGRAPHIC RECORDING. 


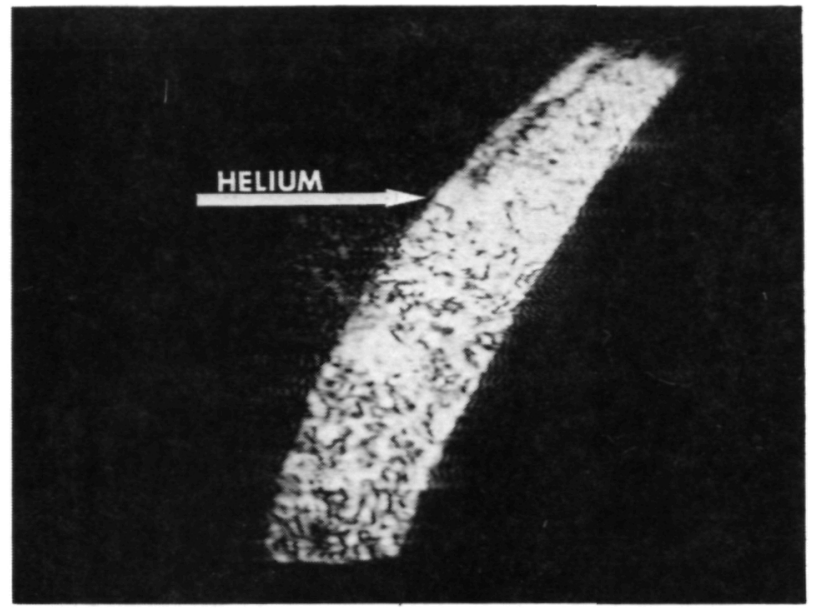

(A). Double pluse With $200 \mu$ S Separation.

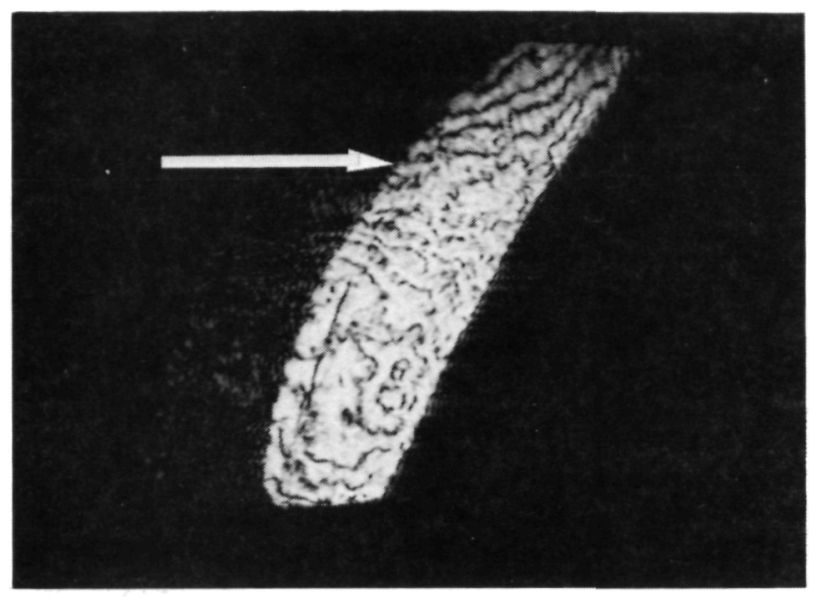

(B). DOUBLE EXPOSURE.

FiguRE 5. - FLOW PATTERNS AT ROTOR POSITION I, 500 RPM (FIRST FIELD OF VIEW).

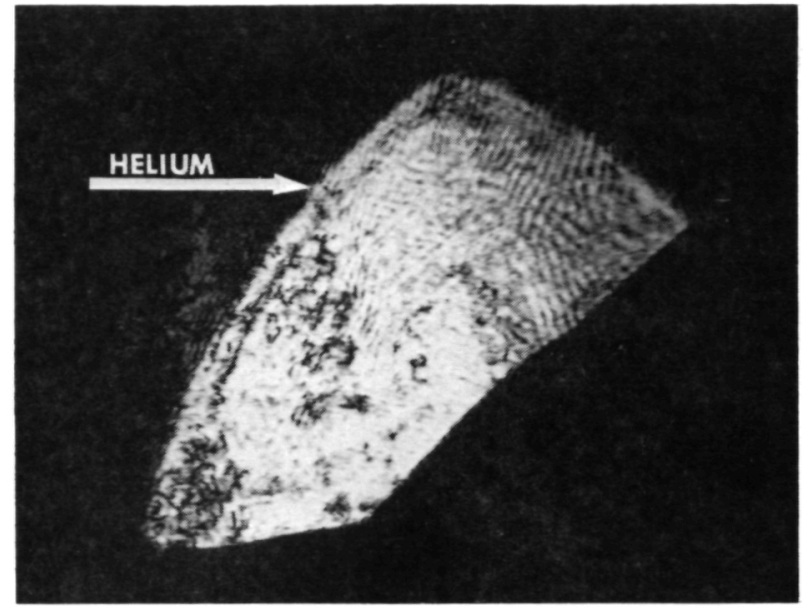

(A). Double PULSE With $50 \mu$ S SEPARATION.

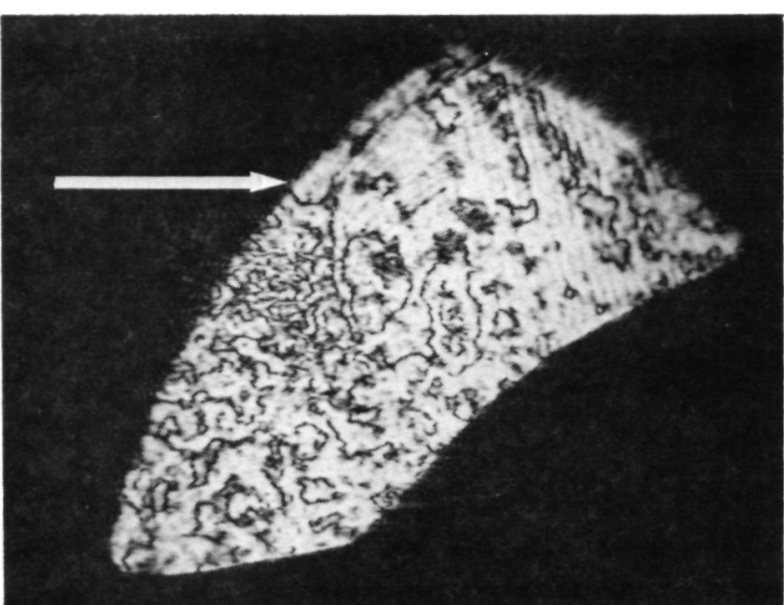

(B). DOUBLE PULSE WITH $200 \mu \mathrm{S}$ SEPARATION.

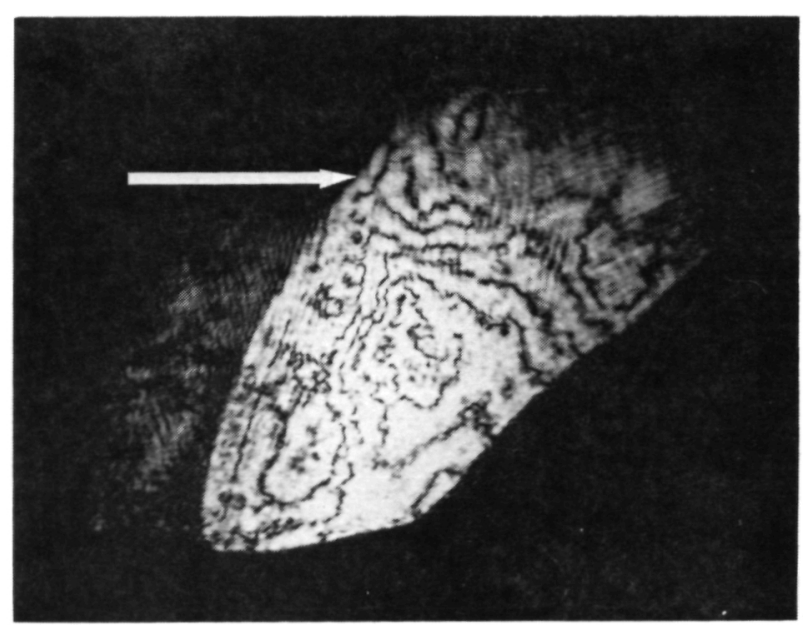

(c). DOUBLE exposure.

FiguRE 6. - FLOW PATTERNS AT ROTOR POSITION II, 500 RPM (FIRST FIELD OF VIEW). 


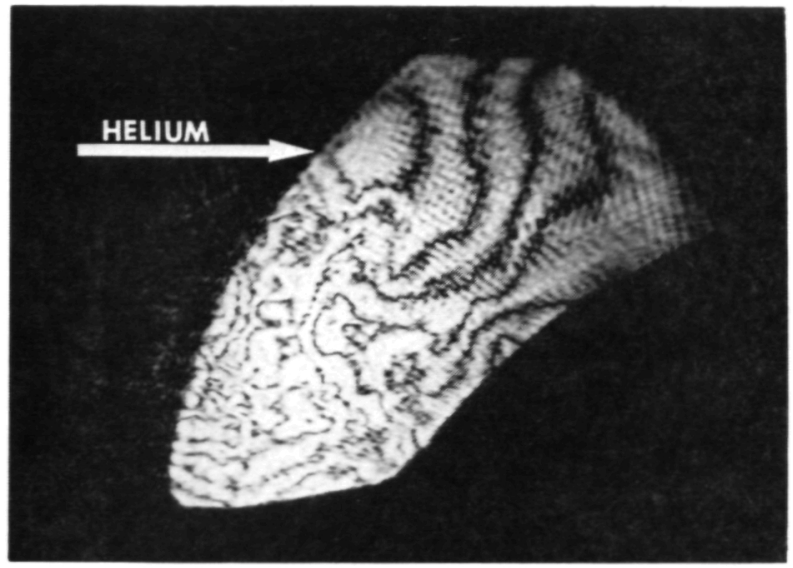

(A). DOUble exposure - First field OF VIEW.

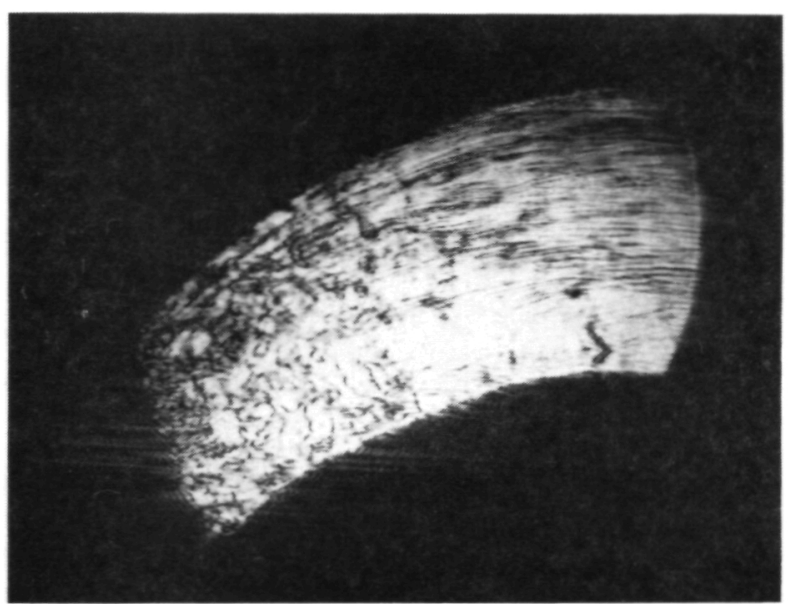

(B). DOUble PULSE With $200 \mu$ S SEPARATION SEDCOND FIELD OF VIEW.

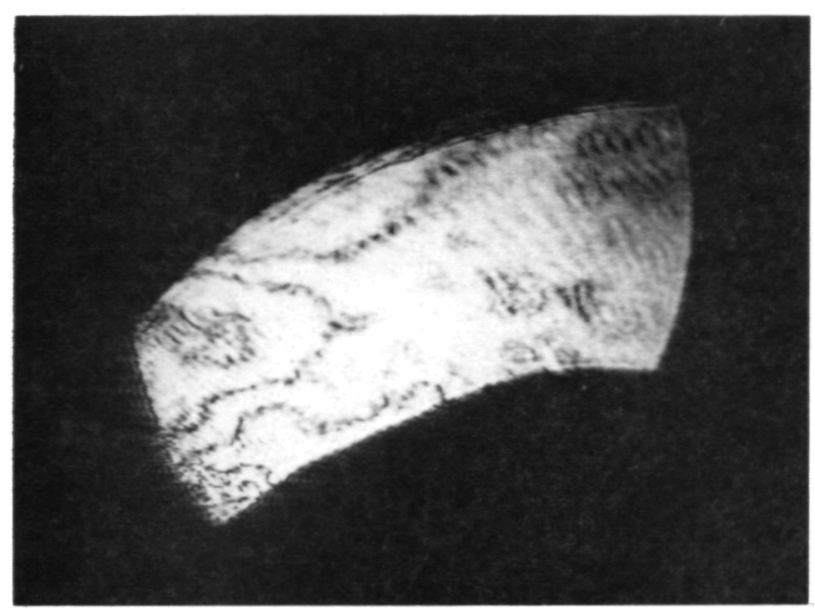

(c). Double EXPOSURE - SECOND FIELD OF VIEW.

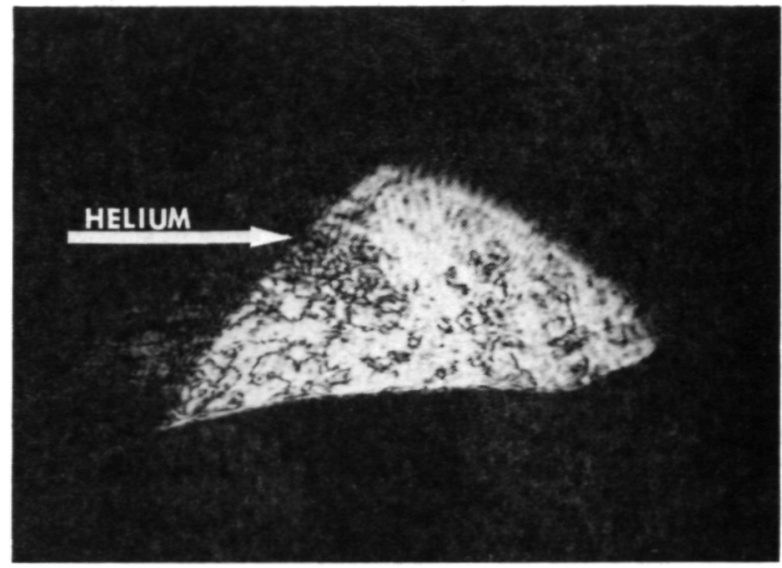

(A). Double pUlse With $200 \mu$ S Separation FIRST FIELD OF VIEW.

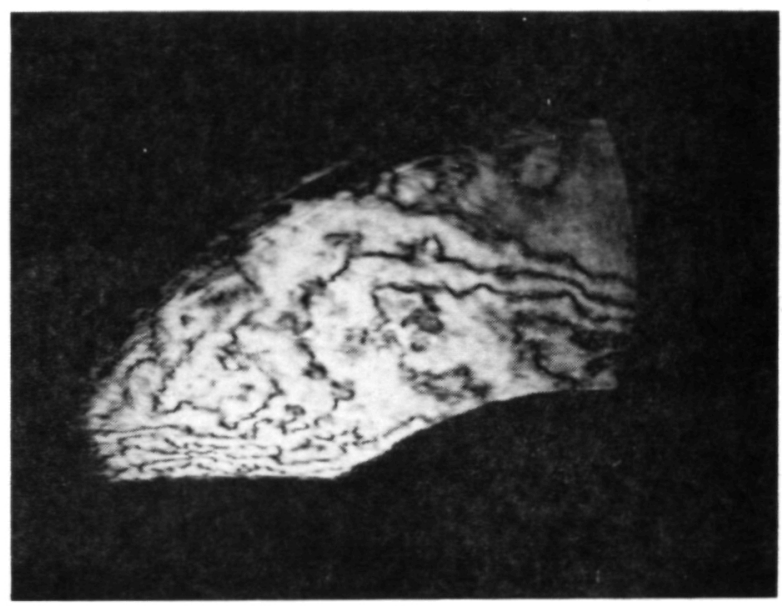

(B). DOUble EXPOSURE-SECOND FIELD OF VIEW.

Figure 8. - Flow PATTERNS AT ROTOR POSITION IV, 500 RPM.

Figure 7. - Flow PATTERNS AT ROTOR POSITION III, 500 RPM. 


\section{ORIGINAL PRES IT \\ OF POOR QUALITY}

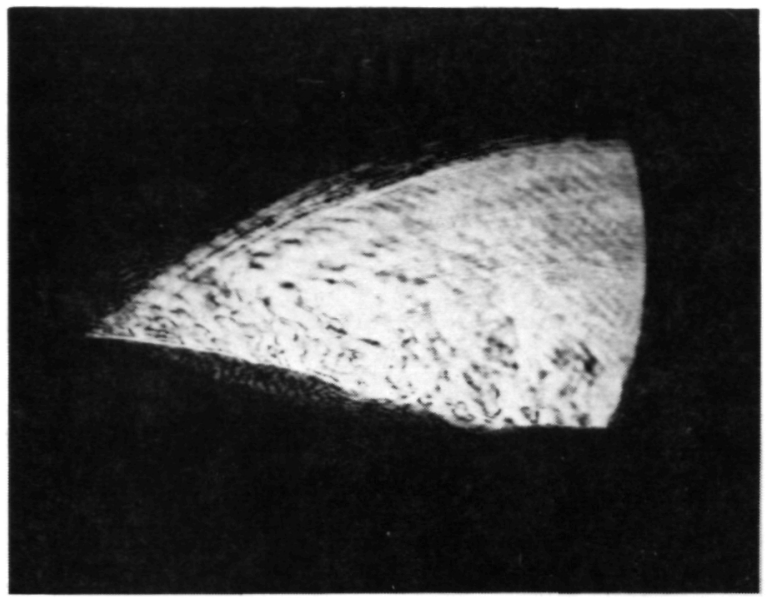

(A) Double PULSE With $200 \mu$ S SEparation.

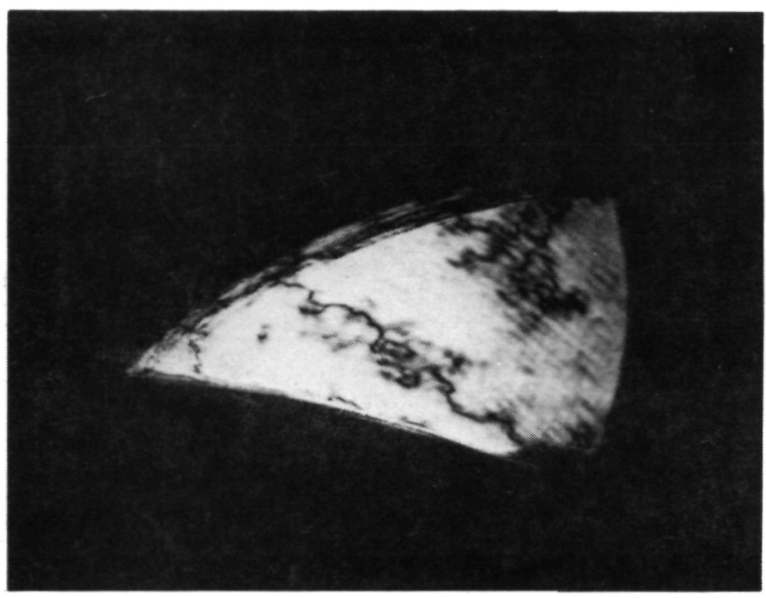

(B) DOUBLE EXPosure.

FigURE 9. - FLOW PATTERNS AT ROTOR POSITION V, 500 RPM (SECOND FIELD OF VIEW).

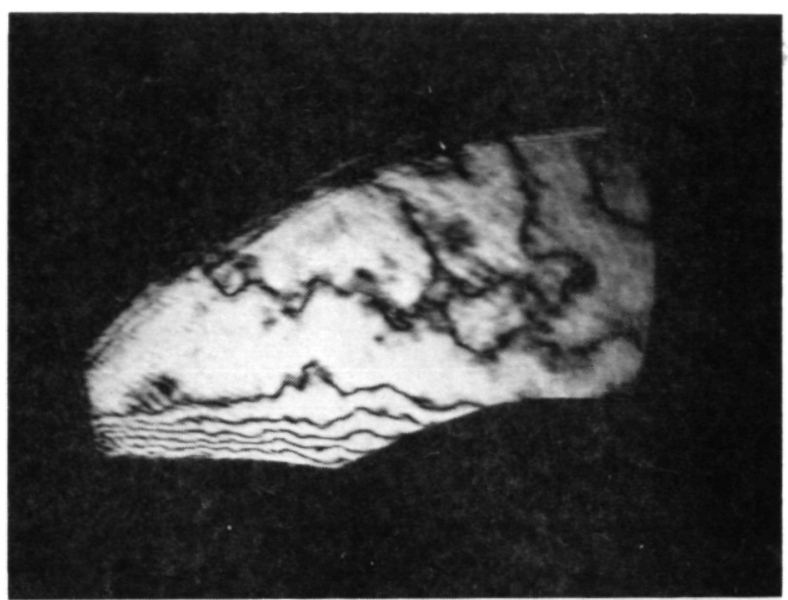

(A) Flow PATtern at 20 pSig.

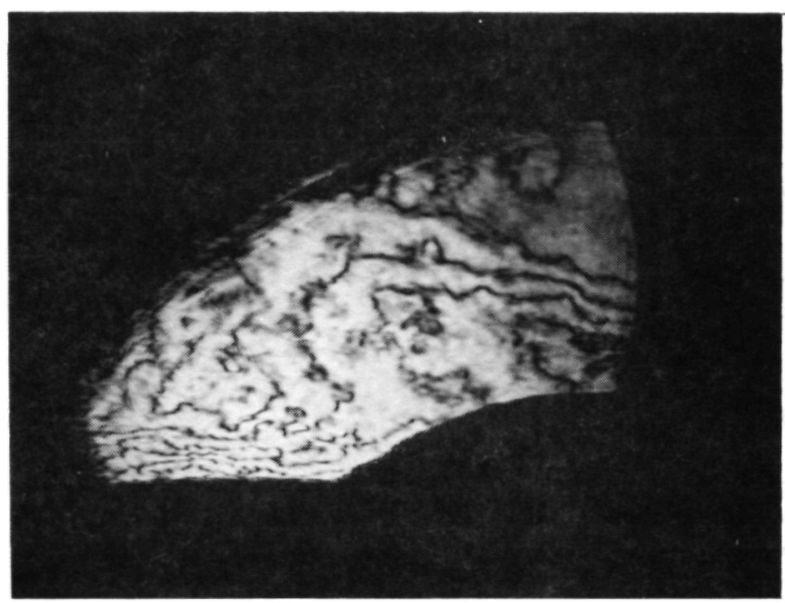

(B) Flow PATTERn AT 10 PISG.

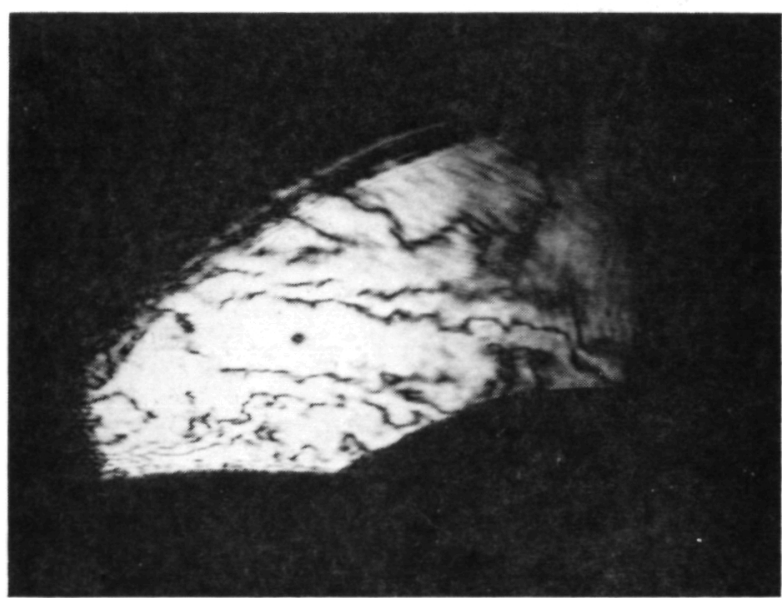

(c) Flow pattern at 6 psig.

Figure 10. - EFFECT OF HEL IUM FLOW RATE ON MIXING, ROTOR POSITION IV. 
ORIGINAL PAGE

OF POOR QUALITY

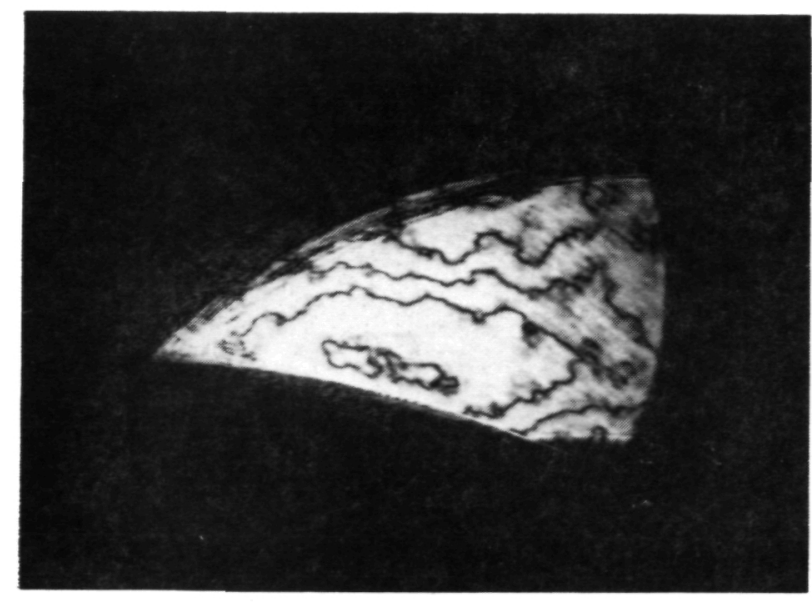

(A) Flow patern at 20 psig.

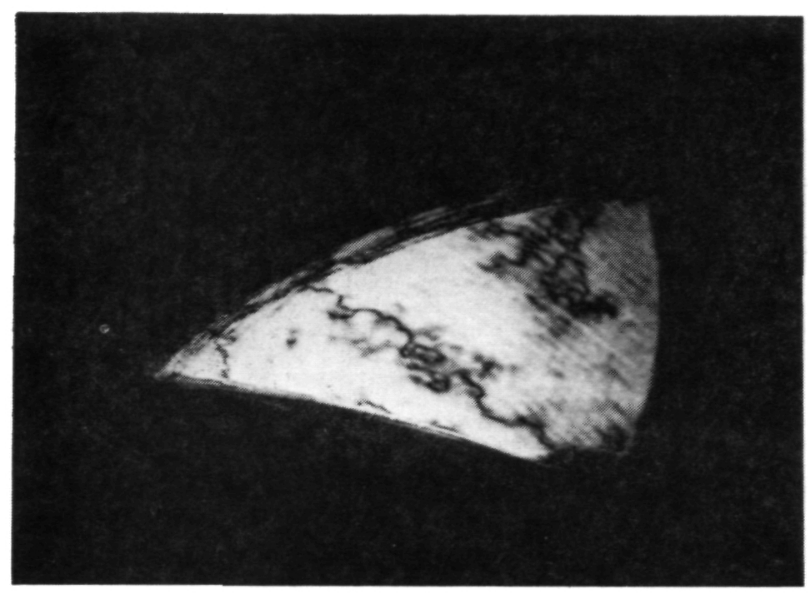

(B) Flow pattern at 10 psig.

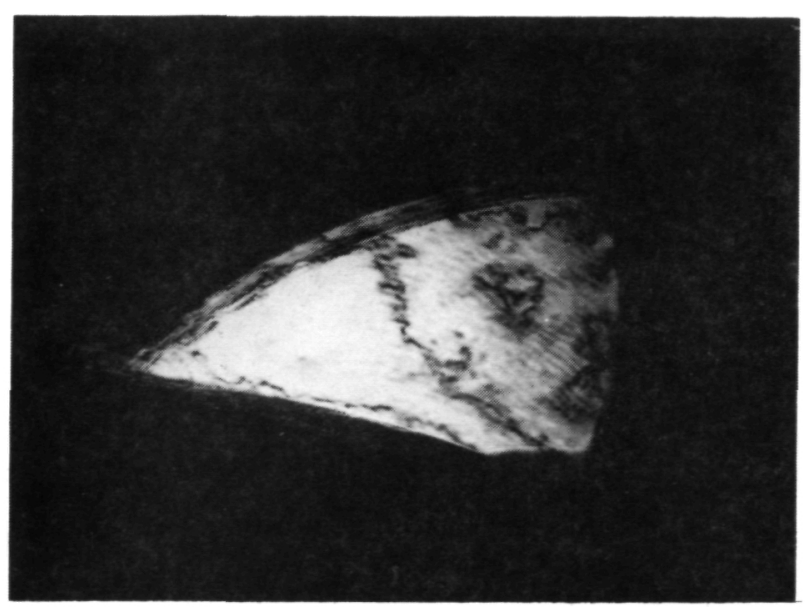

(c) Flow pattern at 6 psig.

FIgURE 11. - EFFECT OF HELIUM FLOW RATE ON MIXING, ROTOR POSITION V.

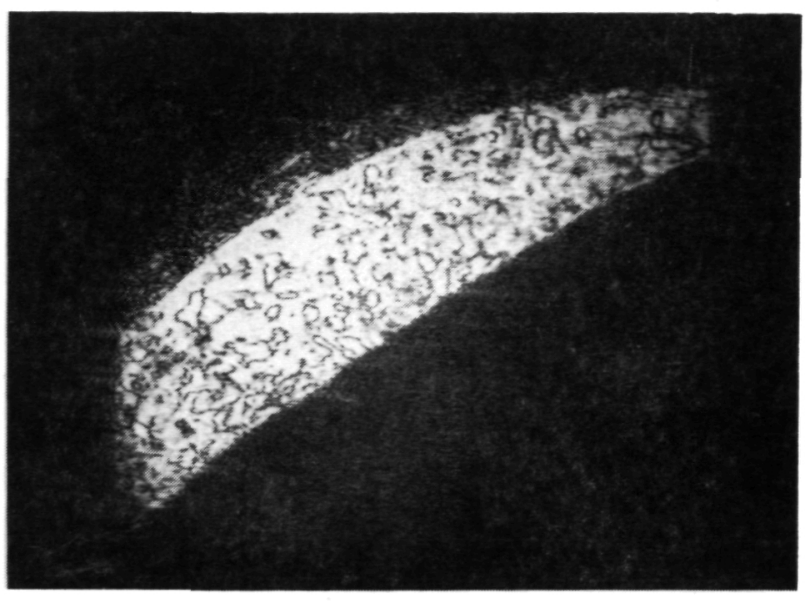

(A) 652 RPM.

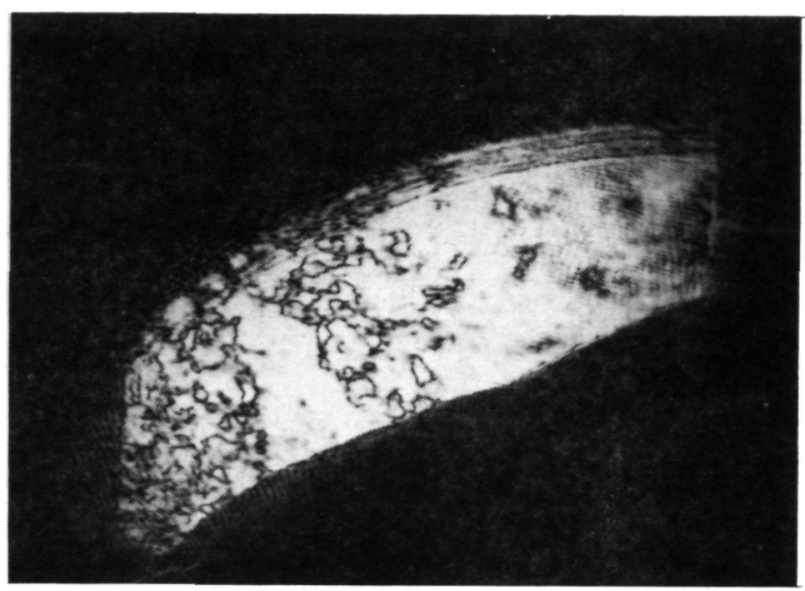

(B) 510 RPM.

Figure 12. - EFFECT OF ENGINE SPEED ON MIXING, ROTOR POSITION II. 


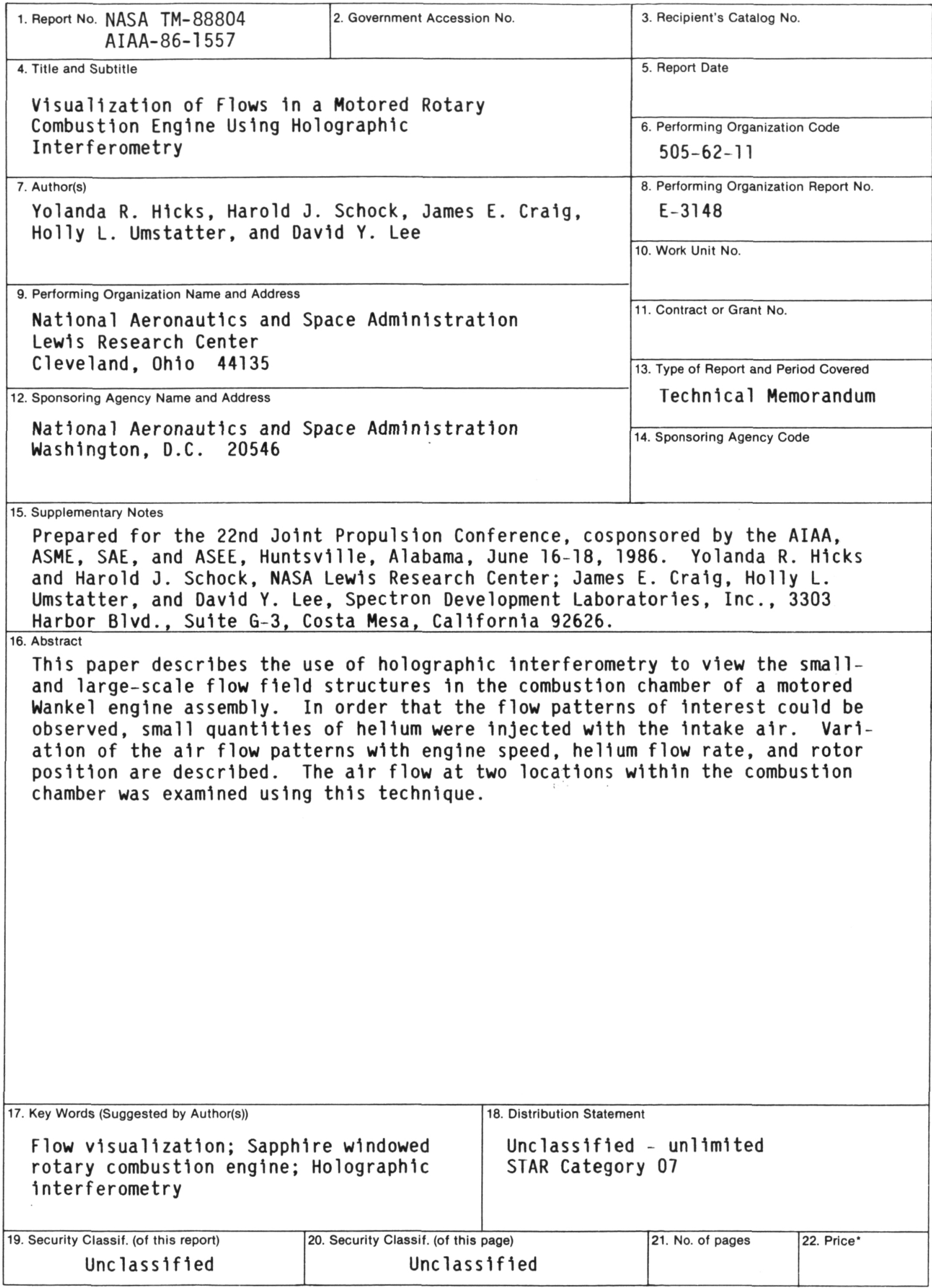

* For sale by the National Technical Information Service, Springfield, Virginia 22161 
National Aeronautics and Space Administration

Lewis Research Center

Cleveland. Ohio 44135

Official Business

Penalty for Private Use $\$ \mathbf{3 0 0}$
SECOND CLASS MAIL

ADDRESS CORRECTION REQUESTED

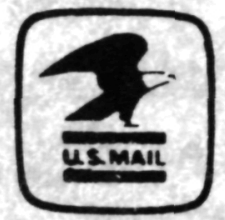

Postage and Fees Paid National Aeronautics and Space Administration NASA-451 